\title{
Patient and public involvement (PPI) in prisons: the involvement of people living in prison in the research process - a systematic scoping review
}

Samantha Treacy ${ }^{1,2}$, Steven Martin ${ }^{3}$, Nelum Samarutilake ${ }^{2}$ and Tine Van Bortel ${ }^{2,3^{*}}$ (D)

\begin{abstract}
Background: Patient and Public Involvement (PPI) in health and social care research is increasingly prevalent and is promoted in policy as a means of improving the validity of research. This also applies to people living in prison and using social care services. Whilst evidence for the effectiveness of PPI was limited and reviews of its application in prisons were not found, the infancy of the evidence base and moral and ethical reasons for involvement mean that PPI continues to be advocated in the community and in prisons.

Objectives: To conduct a review of the literature regarding the involvement of people or persons living in prison (PLiP) in health and social care research focused on: (i) aims; (ii) types of involvement; (iii) evaluations and findings; (iv) barriers and solutions; and (v) feasibility of undertaking a systematic review.

Methods: A systematic scoping review was undertaken following Arksey and O'Malley's (International Journal of Social Research Methodology 8: 19-32, 2005) five-stage framework. A comprehensive search was conducted involving ten electronic databases up until December 2020 using patient involvement and context related search terms. A review-specific spreadsheet was created following the PICO formula, and a narrative synthesis approach was taken to answer the research questions. PRISMA guidelines were followed in reporting.

Results: 39 papers were selected for inclusion in the review. The majority of these took a 'participatory' approach to prisoner involvement, which occurred at most stages during the research process except for more 'higher' level research operations (funding applications and project management), and only one study was led by PLiPs. Few studies involved an evaluation of the involvement of PLiP, and this was mostly PLiP or researcher reflections without formal or independent analysis, and largely reported a positive impact. Barriers to the involvement of PLiP coalesced around power differences and prison bureaucracy.
\end{abstract}

\footnotetext{
* Correspondence: tv250@medschl.cam.ac.uk

${ }^{2}$ Cambridge Public Health, Department of Psychiatry, School of Clinical

Medicine, University of Cambridge, Cambridge, UK

${ }^{3}$ Leicester School of Allied Health Sciences, De Montfort University, Leicester,

UK

Full list of author information is available at the end of the article
}

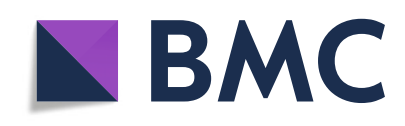

(- The Author(s). 2021 Open Access This article is licensed under a Creative Commons Attribution 4.0 International License, which permits use, sharing, adaptation, distribution and reproduction in any medium or format, as long as you give appropriate credit to the original author(s) and the source, provide a link to the Creative Commons licence, and indicate if changes were made. The images or other third party material in this article are included in the article's Creative Commons licence, unless indicated otherwise in a credit line to the material. If material is not included in the article's Creative Commons licence and your intended use is not permitted by statutory regulation or exceeds the permitted use, you will need to obtain permission directly from the copyright holder. To view a copy of this licence, visit http://creativecommons.org/licenses/by/4.0/. The Creative Commons Public Domain Dedication waiver (http://creativecommons.org/publicdomain/zero/1.0/) applies to the data made available in this article, unless otherwise stated in a credit line to the data. 
Conclusion: Given the very high risk of bias arising from the available 'evaluations', it was not possible to derive firm conclusions about the effectiveness of PLiP involvement in the research process. In addition, given the state of the evidence base, it was felt that a systematic review would not be feasible until more evaluations were undertaken using a range of methodologies to develop the field further.

Keywords: Patient and public involvement in research, Engagement in research, Participatory research, Prison research, People living in prison, People formerly living in prison, Prisoners, Ex-prisoners, Scoping review

\section{Background}

Patient and Public Involvement (PPI) has been defined as "research being carried out 'with' or 'by' members of the public rather than 'to', 'about' or 'for' them" (INVOLVE, 2012). This has been promoted in UK government policy (Health Research Authority, 2017), is supported by their major research funding body the National Institute for Health Services Research (Russell et al., 2019), and national support centre INVOLVE, and has become increasingly prevalent in the UK over the last decade (Ball et al., 2019).

The involvement of patients or the public in research is rooted in social justice and disability rights activism (Beresford, 2002; Glassman \& Erdem, 2014; Macauley, 2017), and aims to move from paternalistic to democratic practices in health and social care with knowledge and expertise shared between 'professionals' and 'patients' leading to better quality and more valid research (Aubin et al., 2019; Hoekstra et al., 2020; Madden \& Speed, 2017). However, the systematic, rapid evidence and literature reviews that have been conducted on PPI in health and social care research have indicated that there is typically a lack of evidence of effectiveness (Samele et al., 2008; Treacy et al., 2019). Although positive impacts on patients, research quality, the research team and research system were widely reported (Ball et al., 2019; Brett et al., 2012), conclusions were severely limited as the research was generally of poor quality, with much of the 'evidence' based on researchers' perceptions rather than on robust evaluation (Aubin et al., 2019; Ball et al., 2019; Cook et al., 2019; Mockford et al., 2012).

In addition, a number of issues were documented that reportedly impeded implementation including: a lack of definition or theoretical basis guiding involvement (Mockford et al., 2012), increased costs and resources (Domecq et al., 2014), differences of opinion regarding the 'representativeness' of the patients and its necessity (Lander et al., 2019; Morgan, 2016), and tokenistic involvement (Madden \& Speed, 2017; Ocloo \& Matthews, 2016). Despite this, much of the literature maintained that PPI arose largely for moral and ethical reasons, which may have resulted in an evidence lag and advocated better evaluations and a focus on overcoming cultural challenges to ensure better implementation (Aubin et al., 2019; Ward, Bailey \& Boyd, 2012).
This paper specifically reviews the literature on the involvement of PLiP in health and social care research, which is also supported by policy on the involvement of 'the public' in research (Health Research Authority, 2017). For the purposes of this paper, PLiPs include people incarcerated in both prisons and jails. The general health of PLiP is typically reported to be poorer than that of people living in the community possibly due to more chaotic lifestyles including alcohol and substance misuse, less access to healthcare and stress related to the 'pains' of imprisonment (Crewe, 2011; Williams et al., 2012). The sharp rise in older PLiP numbers over the last few decades (Lee et al, 2016; Sturge, 2020) has also, inevitably, brought with it an exponential increase in health and social care needs with an estimated $85 \%$ of PLiPs aged over 50 reporting problems (Lee et al, 2019; Hayes et al., 2012; Senior, Forsyth, Walsh et al., 2013). Whilst policy and legislation promotes equivalence between the community and prisons regarding health and social care (Care Act, 2014; Department of Health, 1999), a recent parliamentary inquiry concluded that the government is "failing in its duty of care" to PLiPs (Health and Social Care Committee, 2018). In addition, PLiPs' health and social care issues have reportedly been exacerbated by the restricted regimes and services and suspension of visits applied in prisons in response to the Covid-19 pandemic (Brennan, 2020; Her Majesty's Prison \& Probation Service, 2020), the impact of which have left PLiP and their families in "extreme distress and desperation", particularly those most vulnerable (Prison Reform Trust, 2020, p. 7; Clarke, 2020).

It is unclear how equivalent PLiP involvement in the health and social care research process is relative to that in the community as no reviews of the literature were found. However, PPI in prisons has been described as under-developed (Awenat et al., 2017). A study of prison and research staffs' attitudes towards PLiP involvement demonstrated a lack of understanding and suggested that PLiPs were not seen as potential partners in the process (Johnson et al., 2018). One review outlined the possible ways that PLiPs could be involved, referring to the involvement of forensic mental health service users in research, but no examples of practice in prison were presented (Samele et al., 2008).

Given the extent of PLiP needs and their position as perhaps the most disempowered health and social care 
service users, their involvement in the research process would be highly consistent with the moral and ethical concerns driving public involvement in research (Revolving Doors Agency, 2016). Therefore, it is the aim of this paper to explore the literature for examples of PLiP involvement in the research process and to undertake a systematic scoping review addressing the following research questions:

1. What were the aims of the research which involved PLiPs or people who were formerly living in prison (PFLiP) during the research process?

2. In what ways were PLiPs and PFLiPs involved in the research process?

3. Was PLiP or PFLiP involvement evaluated, and how was this carried out? What were the main findings of these evaluations?

4. What were the main obstacles in involving PLiPs or PFLiPs, and what were the suggested solutions for overcoming them?

5. Would it be feasible to undertake a systematic review of PLiP or PFLiP involvement in health and social care research?

\section{Methods}

Given the lack of reviews of PLiP involvement in health and social care research, a scoping review methodology was considered the most appropriate to explore the aims of the study. Scoping reviews are considered to be particularly useful to systematically scope, chart and synthesise the available evidence in a research field with a view to examining whether a full systematic review could be conducted (Munn et al., 2018). This review used the five-stage scoping review framework posited by Arksey and O'Malley (2005), with reporting guided by the PRISMA extension for scoping reviews checklist and explanation (Tricco et al., 2018) - the completed checklist for this review is available in Additional file 1. The fivestage framework followed in this review were:

Stage 1: Identification of the research question(s) identified in the 'Background' section

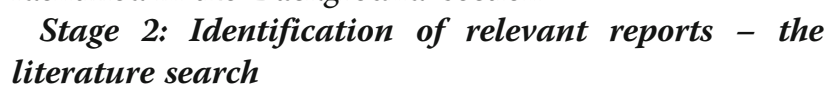

Stage 2: Identification of relevant reports - the literature search

A search strategy to identify review-relevant reports was formulated by the research team, informed by systematic reviews undertaken in relation to patient and public involvement in health and social care research more broadly (Brett et al., 2010; Staley, 2009). Searching included electronic and hand searching components. The electronic database search involved searching ten databases which focused on health and criminal justice, which were: Applied Social Sciences Index and Abstract (ASSIA), Criminal Justice Abstracts, Embase, Medline (OVID), National Criminal Justice Reference Service (NCJRS), Psycinfo, Pubmed, Social Services Abstracts, Sociological Abstracts, and Web of Science (WoS). The search combined research involvement-related terms AND context-related ones (see Table 1), with no date or language restrictions, and covered the full range of publications up until 12th April 2019, with a second updated search from that date until 10th December 2020. Additional file 2 has an example of the search strategy used.

The electronic search was supplemented by a comprehensive hand-search, which involved reference mining, and searches using search engines, specialist prisoner researcher journals and PPI-specific journals, online resources or libraries related to prison(er)s or PPI, recommendations from academic networking sites, and directly contacting authors in the field.

\section{Stage 3: Study selection - inclusion and exclusion criteria}

Papers were selected for inclusion in this review if the following criteria were met informed by the People, Intervention, Comparator and Outcomes (PICO) formula (Richardson et al., 1995):

(i) People: The research process has to involve people who are, or have been, in prison, which includes research conducted by prisoner-led organisations. The research process cannot include prison staff or any other individuals who have not served time in prison.

(ii) Intervention (general): The overall research study has to focus on a health-related topic (including mental or physical health, public health or substance misuse), or be conducted with a health-

Table 1 Search terms used in electronic database search

\begin{tabular}{ll}
\hline Research involvement-related terms & Context-related terms \\
\hline PPI OR PPIE OR "Patient and Public Involvement" OR "prisoner advisor*" OR "participatory health research" & Prison* OR Jail* OR Correctional* OR \\
OR "participatory action research" OR "participatory research" OR "community based participatory & Penitentiar* OR Penal \\
research" OR "service user advisory group" OR "peer research*" OR "advisory committee*" OR \\
"emancipatory research" OR \\
"user(engagement OR involvement OR participation OR representation)" OR \\
"patient(engagement OR involvement OR participation OR representation)" OR \\
"prisoner(engagement OR involvement OR participation OR representation)" OR \\
"offender(engagement OR involvement OR participation OR representation)" \\
\hline
\end{tabular}


related professional such as a mental health professional, a general practitioner (physician) and more. Studies that focus on other prison-focused topics (such as education or regime) with no health focus will be excluded.

(iii) Intervention (specific): The study will need to involve people currently in prison or those who have been in prison in the research process itself, and describe the type of involvement. This 'involvement' can be from any approach or theoretical tradition and can take any form. If PLiP or PFLiP's involvement in the research is as 'participant' or 'subject' only, the study will be excluded.

(iv) Comparator: Any or none. No papers will be excluded on this basis.

(v) Outcomes: No papers will be excluded on the basis of this measure type; the review will chart whether there was an evaluation of PLiP involvement and the outcomes reported. The outcomes of the overall studies will not be reported.

(vi) Context: The overall study has to be set in prison(s) and jails. If the overall health-related study is set in the community, or any other institution, it will be excluded.

(vii)Other criteria (language): Include studies in English, French or Dutch. Exclude papers in all other languages.

(viiiDther criteria (paper type): Only include 'original' empirical research of any design or methodology, and literature reviews. Exclude: commentaries, opinion pieces, newspaper and blog articles, conference abstracts and presentations.

Each of the papers was screened by title and abstract by one researcher, and full-text screening was undertaken by two independent researchers and compared to check for inter-rater reliability (Rutter et al., 2010). Differences of opinion were discussed by the researchers and resolved between them. Papers were thus included if they presented health research in prison with PLiP or PFLiP undertaking any research activities as part of the study.

\section{Stage 4: Charting the data - data extraction}

One researcher extracted data from all of the papers selected, with a second independent researcher extracting data from a third of the papers to check for consistency. Where differences arose, they were resolved between the researchers and consensus reached. Both researchers used an extraction template informed by the PICO formula, and included: author, date, country, overall study aim, aim of prisoner involvement, type of PPI, sample description (if applicable), type of PLiP involved (serving or ex- prisoner), type of prison study situated in, PPI evaluation (whether and how), PPI outcomes on PLiP and research(er), obstacles and recommendations made for PLiP involvement. In addition, there was a section that required extracting data on the research activities which PLiP and PFLiP were involved in. This section combined and followed the categories of research activity suggested by INVOLVE (adapted by Jacobs et al., 2017) and the THIS Institute (Marjanovic et al., 2019), which were conceptualisation, design, fund/commission, undertaking research, analysis, dissemination, evaluation, and implementation. The activity categories were added to when other research-related activity recurred in a number of the papers.

Stage 5: Collating, summarising and reporting results - data analysis

The nature of the papers selected for this review precluded any form of meta-analytic synthesis. The focus was on charting the involvement approaches and activities as described in the papers, and a narrative approach was undertaken to synthesise the findings where reported (Popay et al., 2006) as these were wholly qualitative.

\section{Results}

The literature search returned 8880 papers of which 7733 remained after duplicates were removed. Following screening, thirty-nine papers were selected for inclusion in this scoping review, having met the requisite review criteria. The stages of the screening process undertaken to select the papers are depicted in Fig. 1.

An overview of the included papers is given in Table 2, which is split between papers that used a broadly participatory approach to PLiP/PFLiP involvement $(n=24)$, and papers that used other approaches $(n=14)$. One review of the literature was also included. The table presents the key features of each paper relating to PLiP/ PFLiP involvement as well as evaluation details, main findings and recommendations, where reported.

The majority of the included papers were from the United Kingdom $(n=19)$ or North America $(n=17,10$ papers from Canada, 7 from the USA), with two more from Australia and one from Malaysia. It is of note that seven of the Canadian papers were generated around one research programme, and two further papers involved some of the same research team. Sixteen of the papers involved only PLiPs in the research process, fourteen included only PFLiPs, and eight involved both PLiPs and PFLiPs. The review paper did not appear to involve people who were or had been in prison in the review process. The numbers of PLiPs or PFLiPs involved in the papers ranged from two to approximately 200 . Whilst sixteen papers did not report the gender 


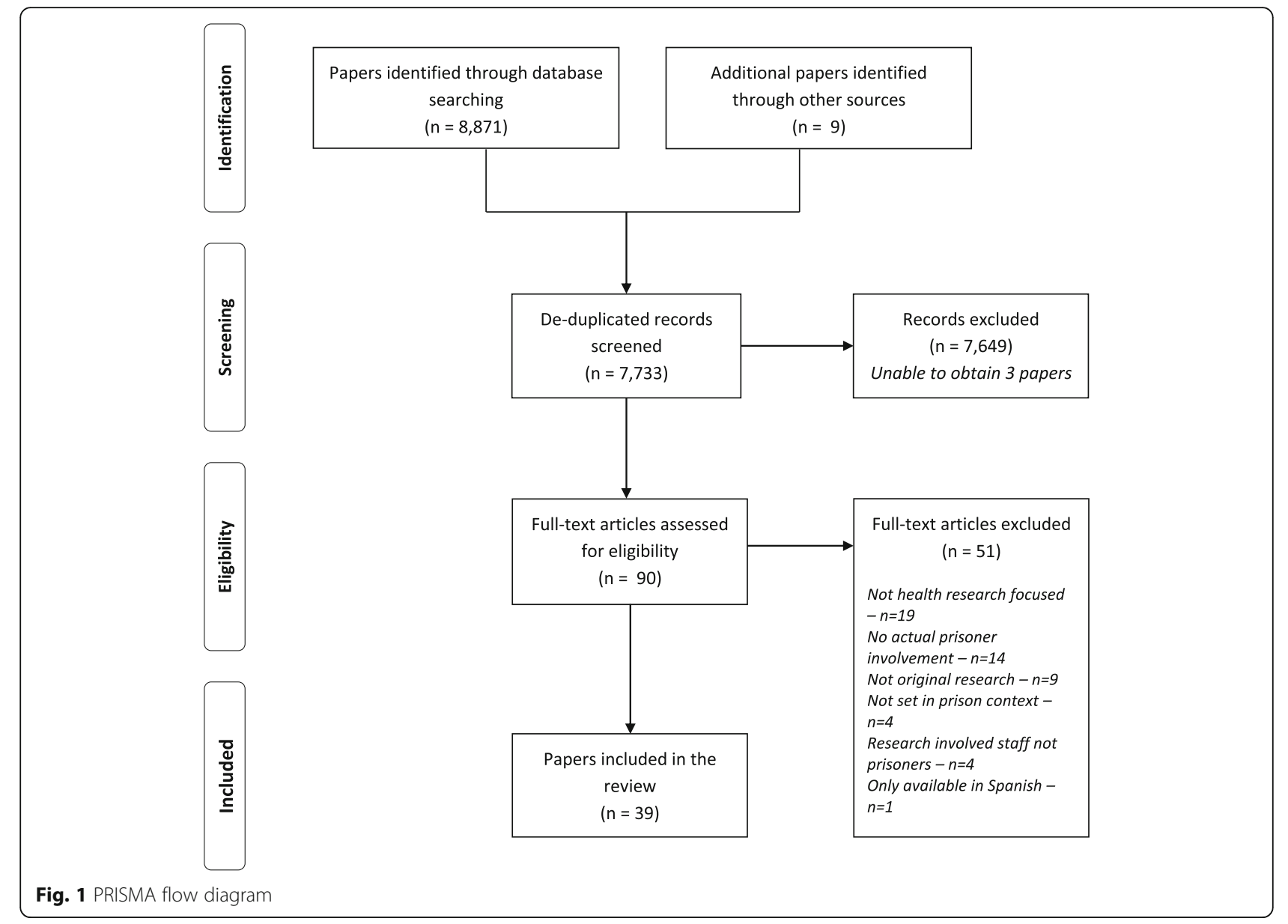

identities of the PLiPs or PFLiPs involved, and less reported on other demographic details, twelve papers involved females, seven involved males, and four papers included both males and females in the research process. In terms of payment, three studies reported that PLiPs ( $n=1$, paper 5$)$ and PFLiPs $(n=2$, papers: 28,36$)$ were paid. A further four papers (papers 9-10,12,17), all from one research programme, described how involvement in the research team became a prison work placement, ultimately resulting in payment at prison work rates.

\section{Research question one: what were the AIMS of involving} people who were or had been in prisons in the research process?

As shown in Table 2, the main aims of PLiP or PFLiP involvement were to make the research more 'valid', legible or applicable to prisoners ( $n=19$, papers5,6,8,10,15,18,20,21,23-28,30,32,35-37); to determine the feasibility as well as benefits and challenges of PLiP or PFLiP involvement in the research process overall ( $n=7$, papers $3,5,11-13,16,22)$; to empower PLiPs or PFLiPs, advance social justice or detail commissioned prisoner-led work $(n=8$, papers
$1,5,9,14,19,25,35,38)$, and to increase the chances of research success or sustainability $(n=3$, papers $4,26,28)$.

Research question two: in what ways were people who were or had been in prison involved in the research process?

PLiP or PFLiP involvement largely happened within a research-specific group, team or advisory panels, which mostly worked together with academic researchers $(n=$ 26 , papers $1-6,8-12,14-17,19,20,25,27-33)$. Six papers also detailed the involvement of PLiPs or PFLiPs on trial or project steering committees (papers 4,6,31-33,38), in an expert symposium and listening exercises $(n=1$, paper 35$)$; and as a co-applicant on projects $(n=2$, paper 31,32 ). One study included was also entirely PFLiP-led and managed research (paper 38).

Figure 2 shows how PLiPs or PFLiPs were involved in each part of the research process. The majority of papers involved PLiP or PFLiPs in generating ideas or, research questions or conceptualising the research and evaluation $(n=23)$. A very high number of papers involved people in research design $(n=32)$, predominantly in co- 


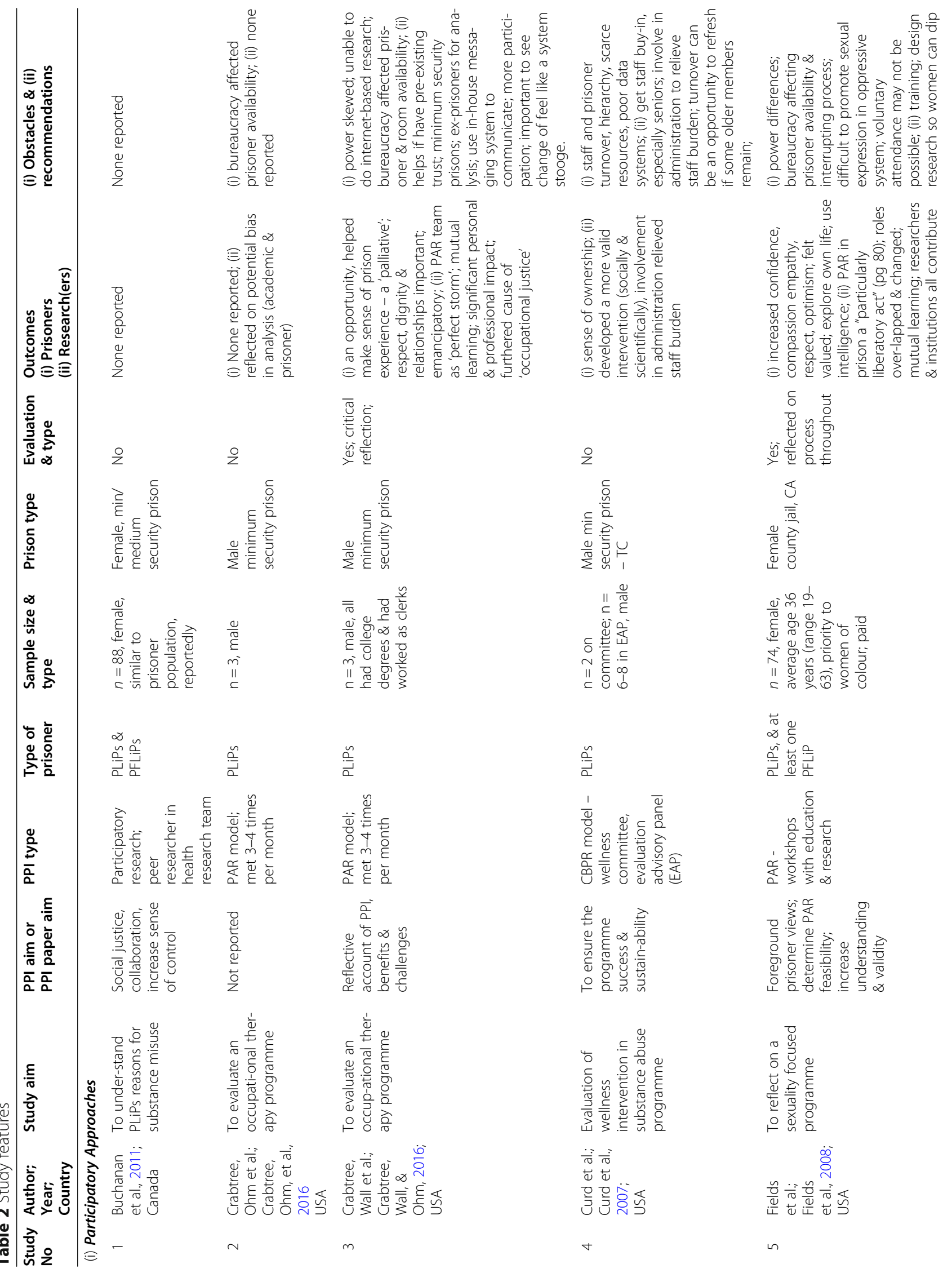




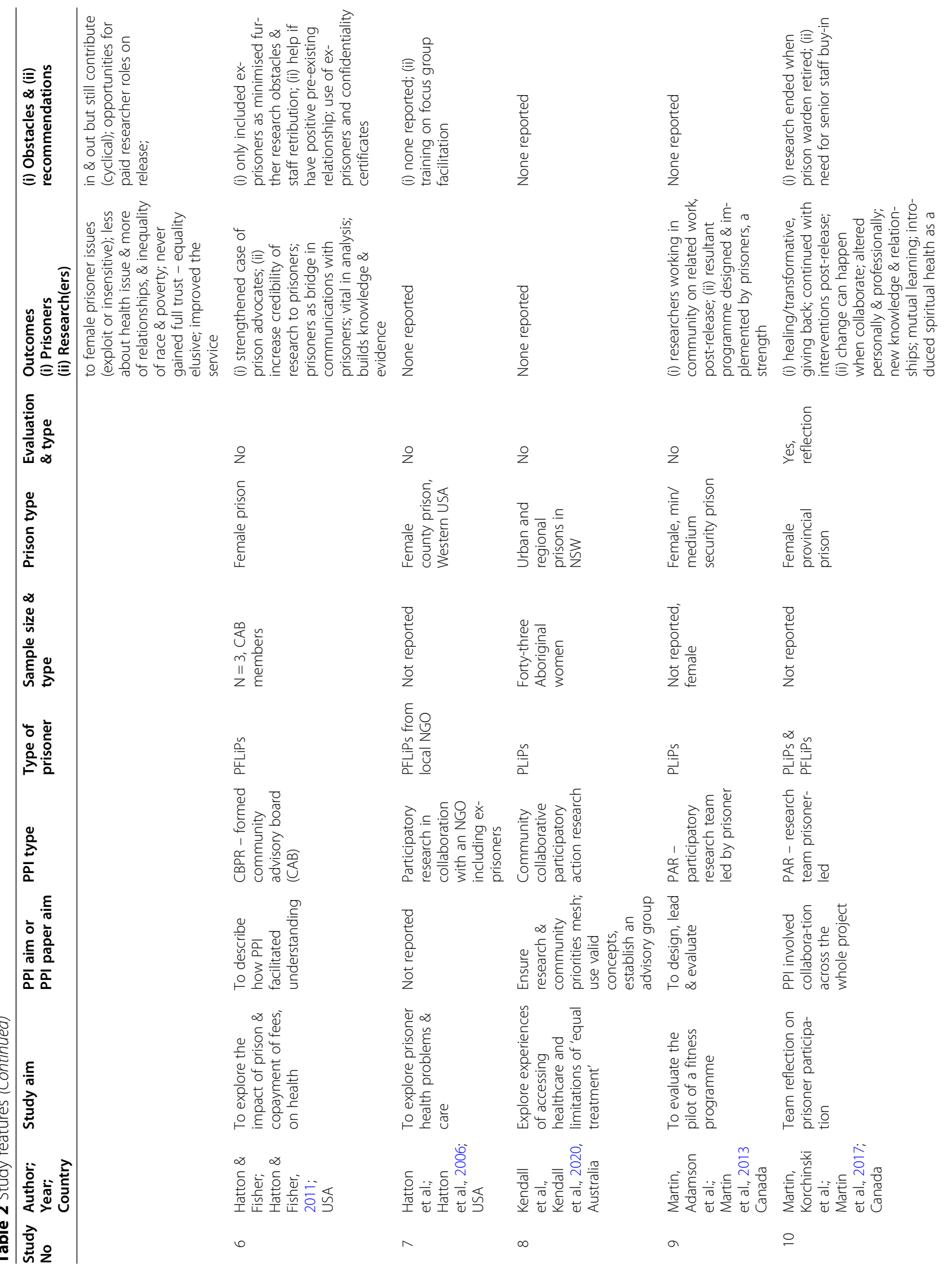




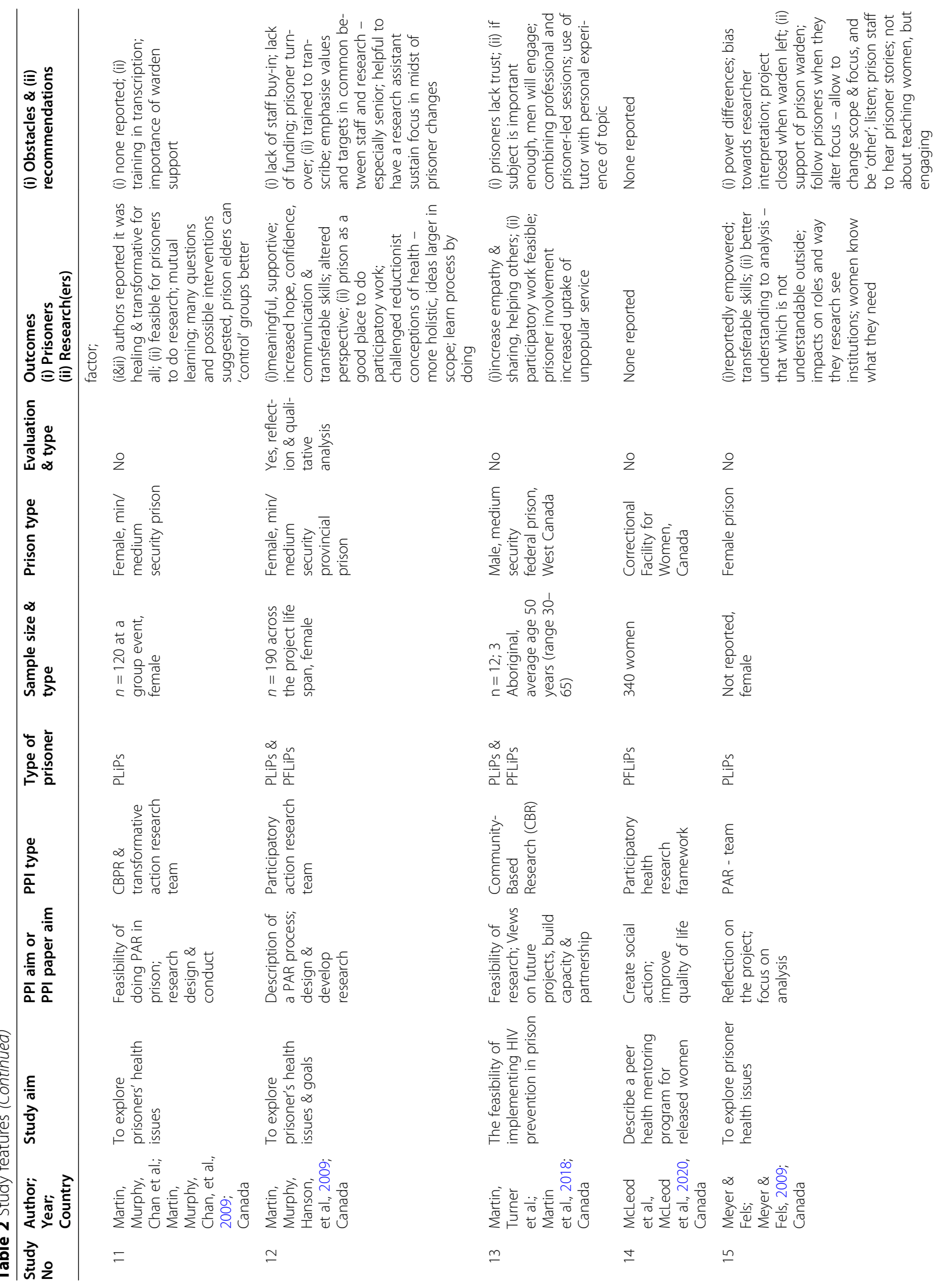




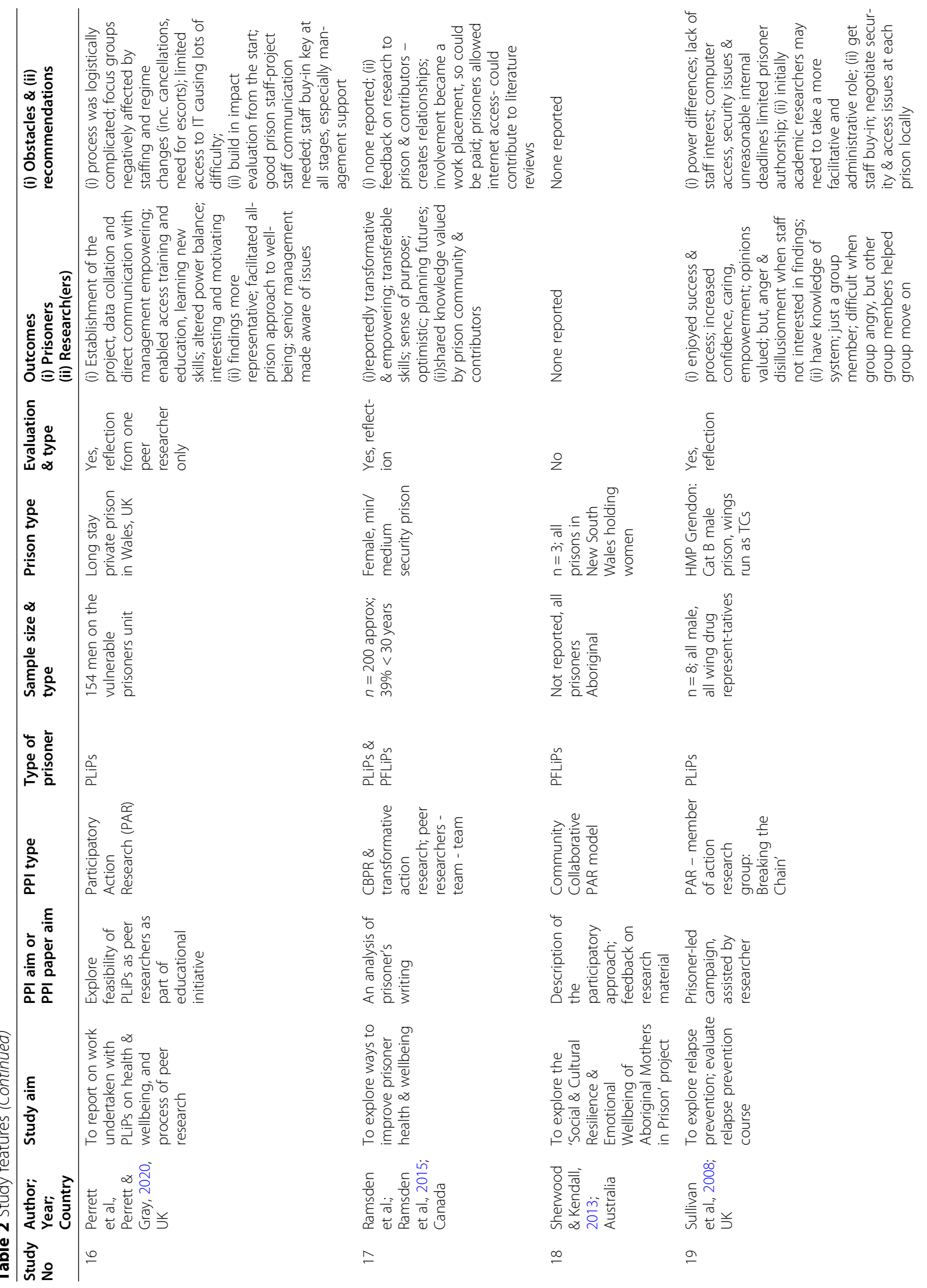




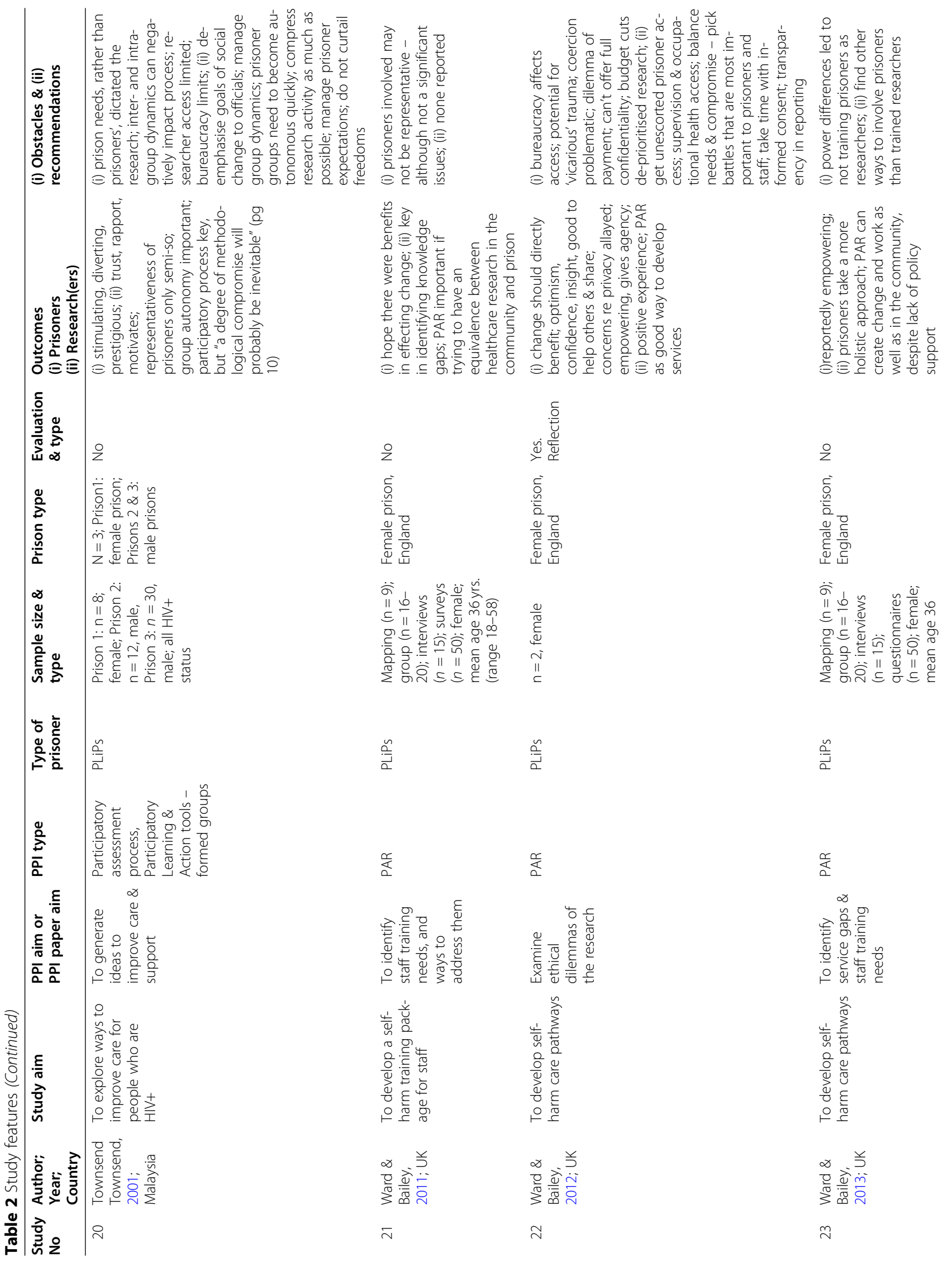




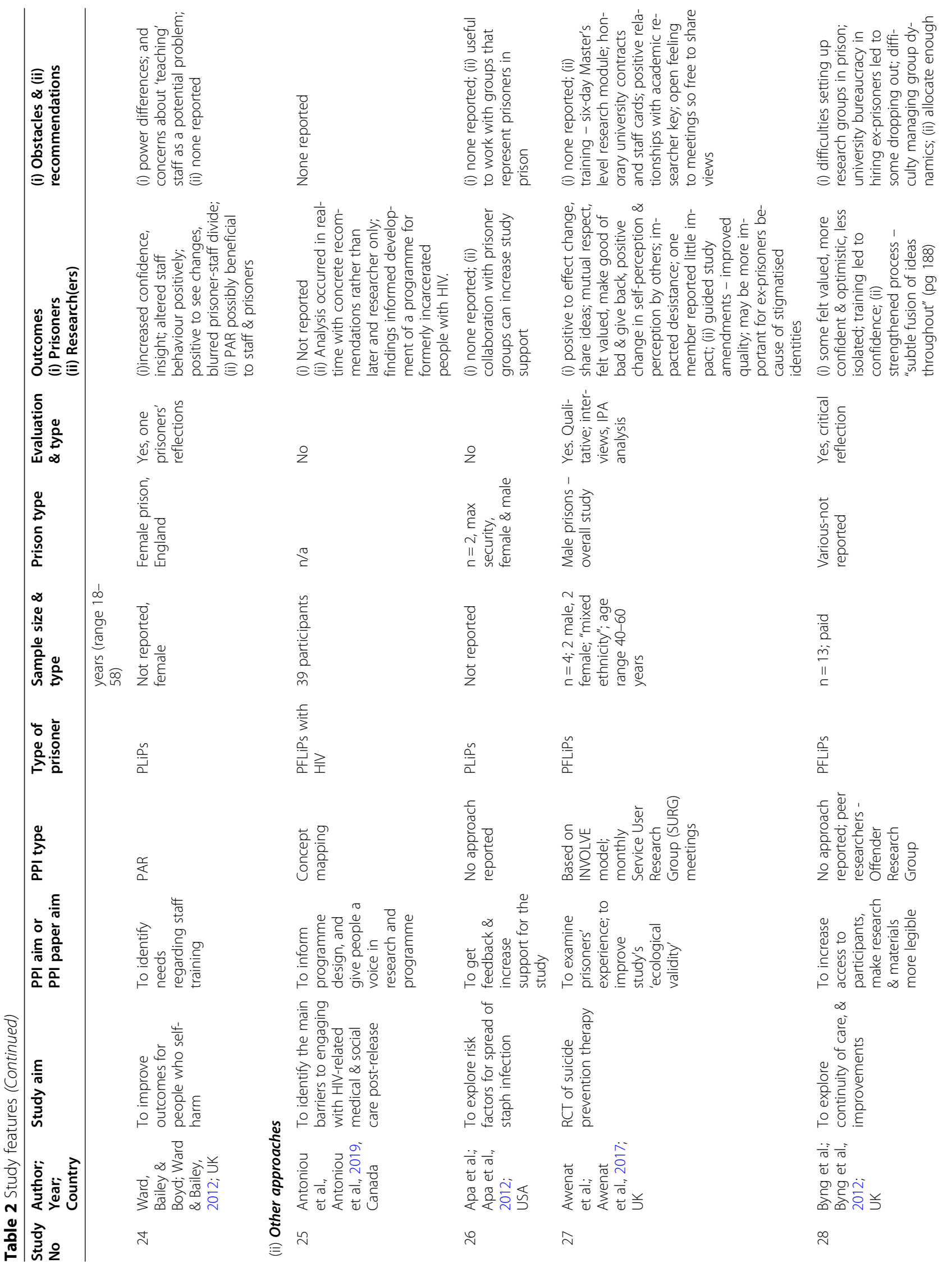




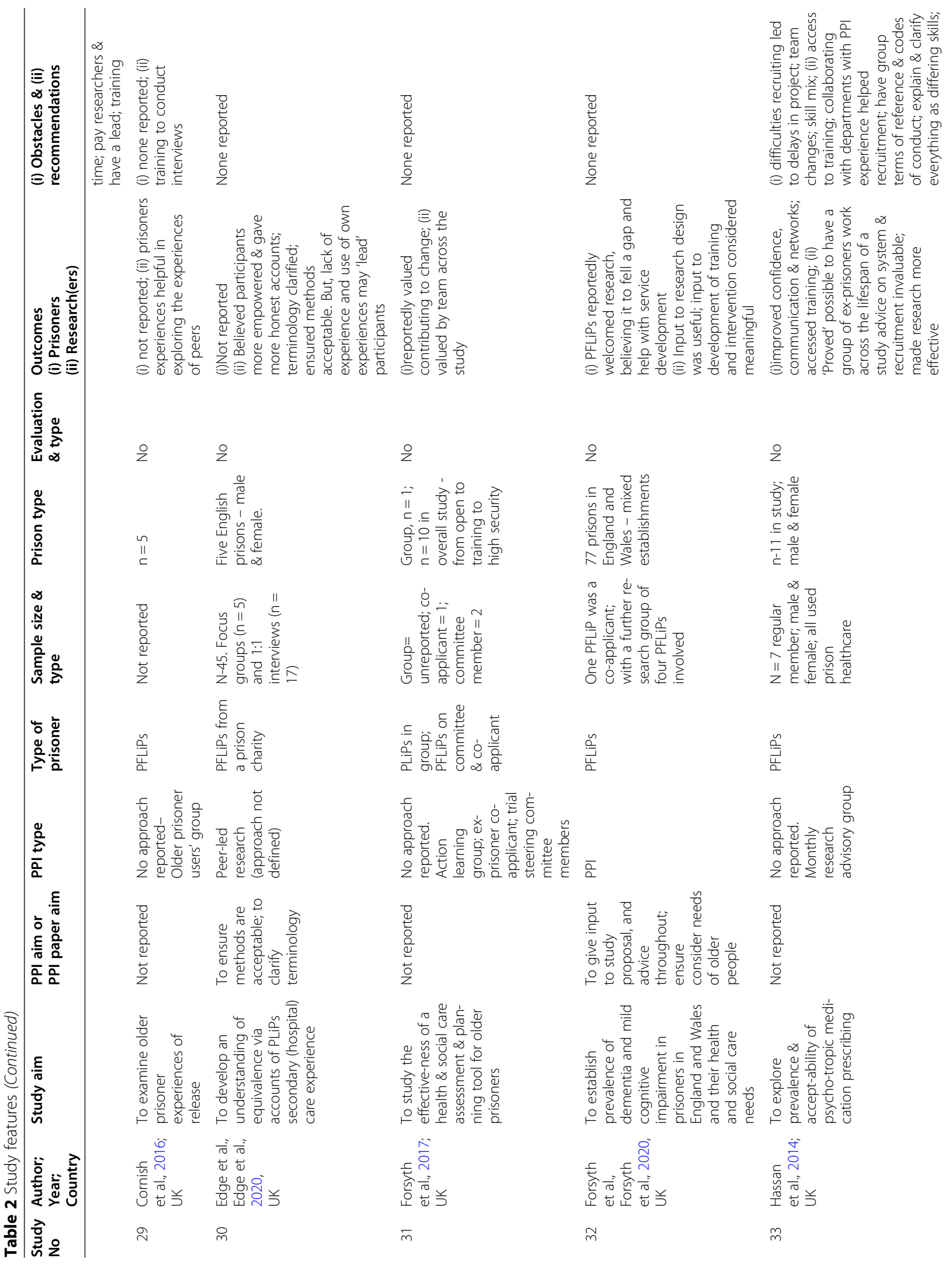




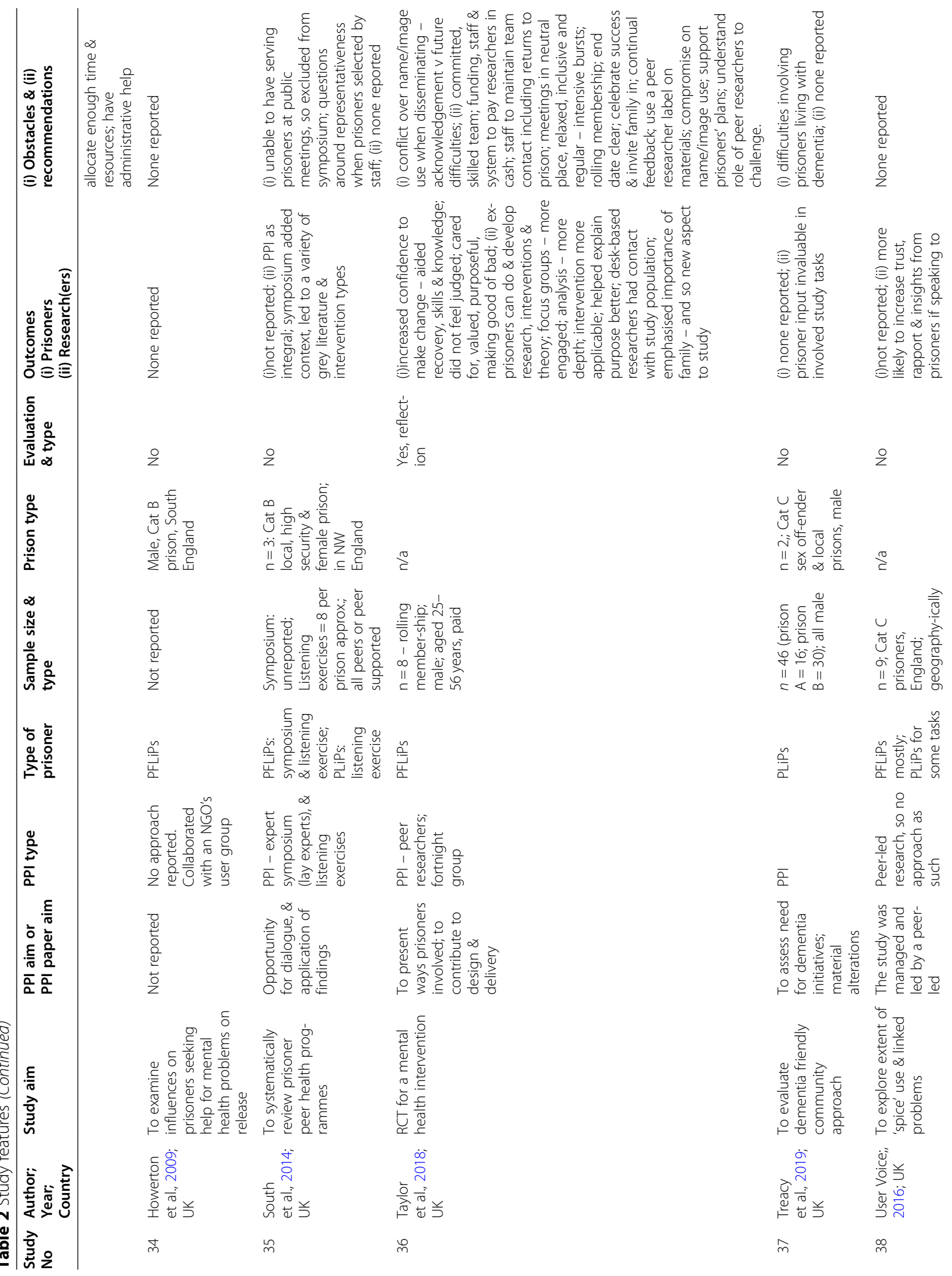




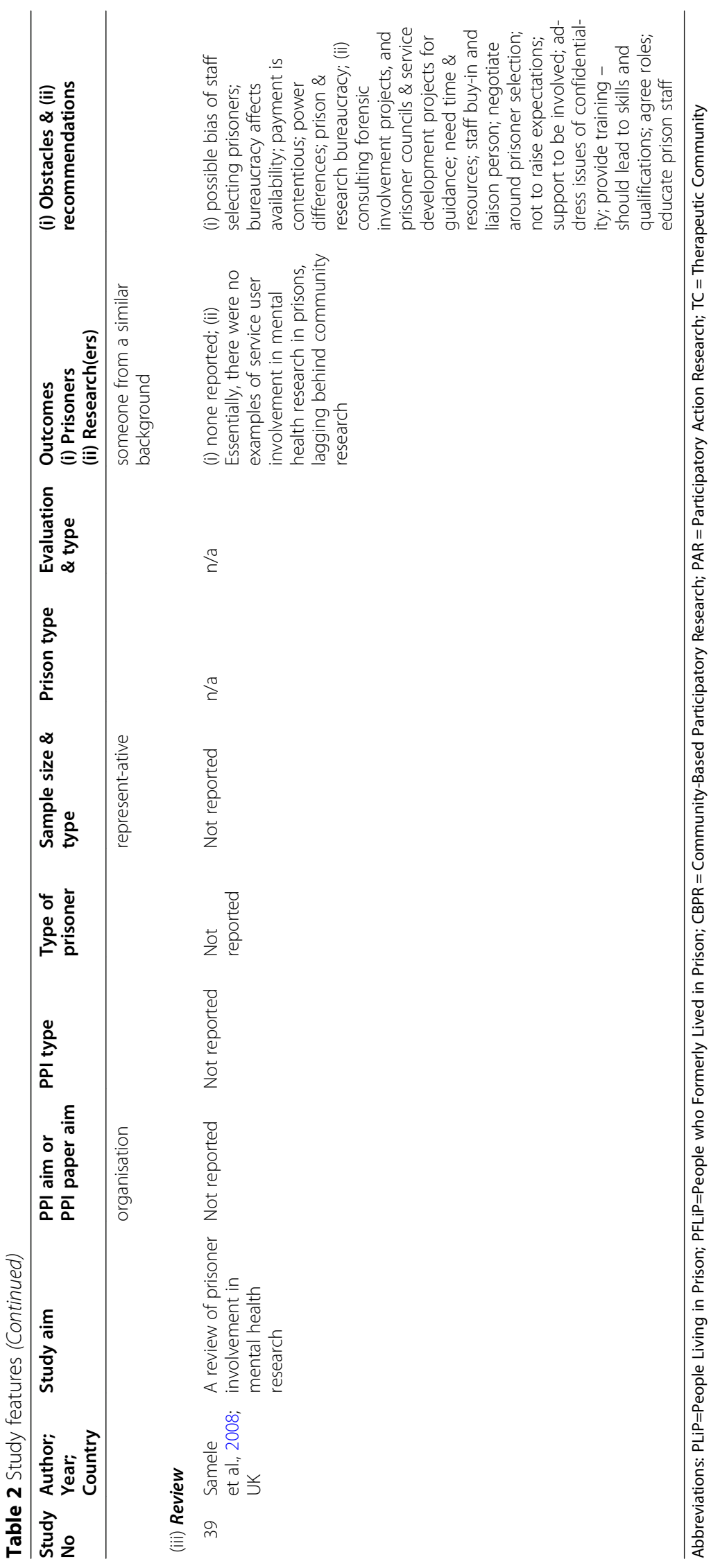




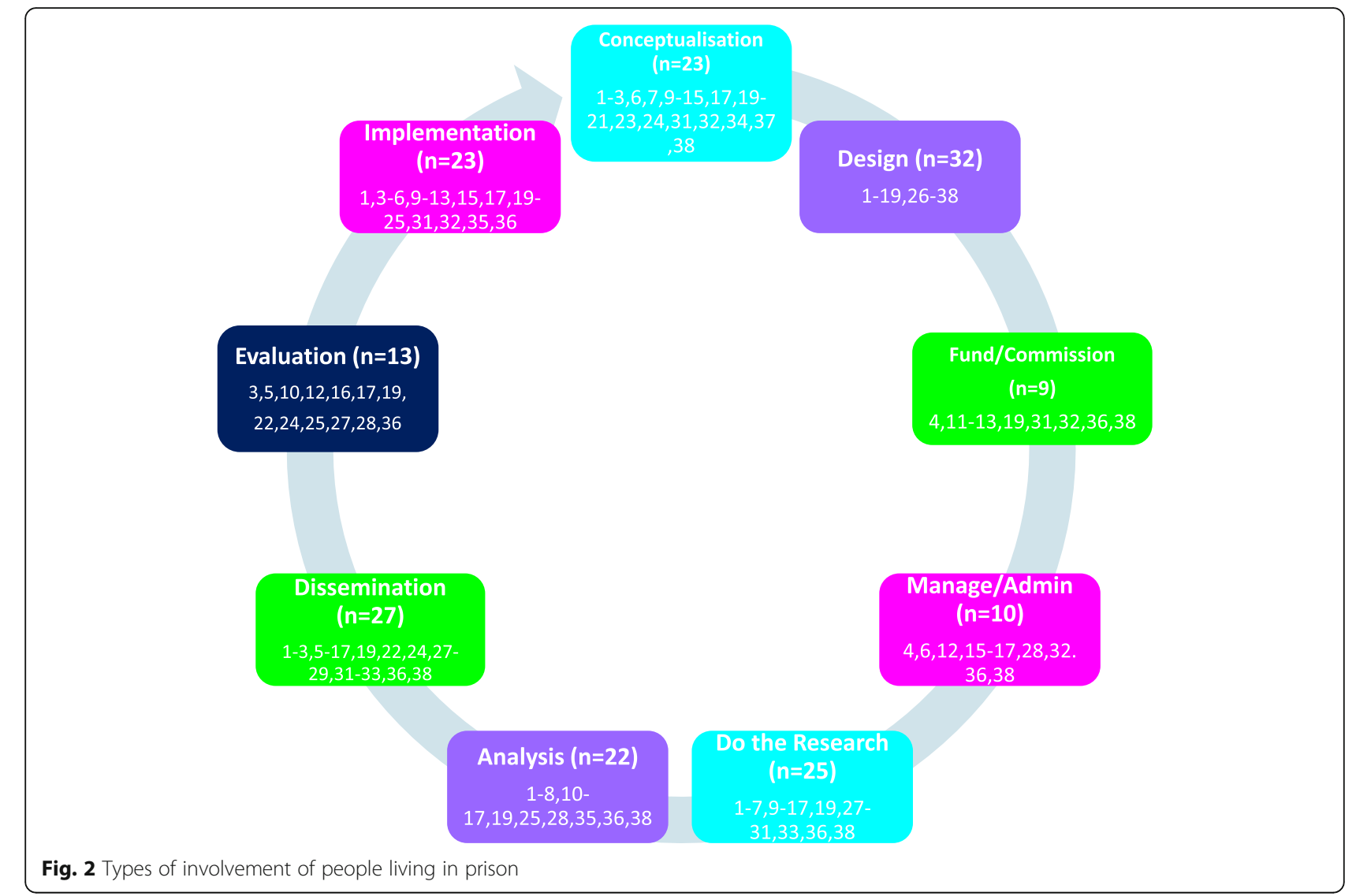

designing or feeding back on research materials $(n=24$, papers $1-6,8,11-19,28-30,33,34,36-38$ ), with some studies also reporting involvement in overall research design ( $n=16$, papers $3-5,7-11,16,18,19,27,28,32,33,35)$. The majority of papers also involved PLiPs or PFLiP in undertaking research $(n=25)$ largely in collecting questionnaires $(n=10$, papers $1,9-11,13,14,16,17,19,38)$ or conducting or co-conducting interviews and focus groups ( $n=14$, papers $1-3,5-7,10,16,19,28-30,36,38)$; and, in dissemination $(n=27)$ with PLiPs or PFLiPs authoring or co-authoring papers $(n=22$, papers 1 $3,5,9-12,14-17,19,22,24,28,29,31-33,36,38)$, and presenting or co-presenting findings $(n=13$, papers $3,5,6,10$ $12,15-17,19,27,33,36)$. A number of studies $(\mathrm{n}=22)$ also involved individuals in feeding back views on preliminary findings, or in the interpretation and analysis of qualitative data, with involvement in quantitative analysis explicitly reported by only two studies, one of which was led by PFLiPs (papers 19,38). This was despite the majority of papers employing a mixed methodology $(n=$ 22; papers $1,3,4,6,9,12-14,16,18-21,23,24,28,31,32,34,36-38$ ), and a further two using a quantitative approach (papers 26,33). The remaining papers used a qualitative methodology or were a review. A large number of studies also involved PLiPs or PFLiPs feeding into, planning or implementing resultant prison programmes or service changes $(n=23)$.
PLiPs and PFLiPs were less involved in funding or commissioning applications $(n=9)$, with only three papers reporting PLiPs or PFLiPs as co-authoring, or coapplying for funding applications (papers 12,31,36), and two PLiP and PFLiP-led research teams were commissioned to undertake research (papers 19,38). In addition, only ten papers described involvement in research administration or management which mostly included taking responsibility for the functioning of the research team (papers 4,6,12,15,17,36,38), but also in training research staff (paper 36), and interviewing prospective academic researchers (paper 28). Lastly, there were only thirteen papers that detailed the involvement of PLiPs or PFLiPs in project evaluations, which is described further in Research Question Three.

\section{Research question three: was prisoner involvement} evaluated, and how? What were the main findings?

The majority of the papers presented no evaluation of PLiP or PFLiP involvement $(n=26)$, and indeed the included literature review on prison mental health research found no studies that evaluated the involvement of PLiPs or PFLiPs in the research process (paper 39). Of the twelve papers that did present some evaluative detail, this mostly took the form of PLiP or PFLiP (critical) reflections (papers 
$3,5,10,12,16,17,19,22,24,27,28,36)$; one paper subjected the reflections to a qualitative analysis (paper 12), and another paper involved interviewing PLiPs and analysing the data qualitatively (paper 27).

The findings of the papers' 'evaluations' were broken down into impact of involvement on (i) the PLiPs and PFLiPs and (ii) the research and researchers. It is of note, that whilst a number of the papers did not present evaluative or reflective detail, some papers did include authors' observations on impact, which will also be included here. Regarding (i) impact on PLiPs and PFLiPs, the papers mostly reported positive findings in relation to emotional effects - with increased confidence, optimism and empowerment $(n=12$, papers 5,12,15$17,19,22-24,28,33,36)$, healing, compassion and giving back ( $n=9$, papers $5,10,11,13,17,19,22,27,36$ ), and understanding and developing a more positive perspective on themselves $(n=7$, papers $3,5,9,10,20,27,29)$. It was also reported that PLiPs and PFLiPs found the work meaningful and purposeful $(n=6$, papers $12,16,17,19,20,36)$, emancipatory $(n=3$, papers $3,5,27)$, that they felt valued and respected $(n=6$, papers $3,5,19,27,28,36)$, and that they appreciated the transferable skills and knowledge that they learned $(n=6$, papers $12,15-17,33,36)$, and the opportunity to be involved in service change and future research work $(n=8$, papers $3,5,9,10,20,27,29,32)$. One paper also suggested that involvement had also increased desistance (paper 27). There were very few negative findings reported, with one paper each respectively reporting: frustration at not being listened to (paper 19), concerns about personal privacy (paper 22), and - more neutrally - that the involvement work had had little impact (paper 27).

The impact of PLiP and PFLiP involvement on (ii) the research process and/or the researchers, largely focused on the process. There were reports that involvement increased understanding and knowledge with PLiP or PFLiPs offering new or more 'holistic' insights $(n=10$, papers 5,6,10-12,15,16,19,21,23), and enhancing the validity, quality or applicability of the research $(n=12$, papers $4,9,16,25,27,28,30,32,33,35,36,38)$. In addition, seven papers stated that PLiP work contributed to the success of the research (papers 6,10,13,20,22,26,28), co-created service change ( $n=8$, papers $5,10,13,16,21,23,25,32)$, and six papers reported that involving PLiP in the research process was feasible (papers 11,13,16,24,33,36). Some of the researchers also reflected on the mutual learning that took place during the process $(n=3$, papers $3,10,11$ ), the personal transformative impact on them and their perspectives $(n=4$, papers $3,10,11,22)$, and the impact on them professionally $(n=4$, papers $3,5,10,15)$, including reflecting on their role and purpose, and of the sometimes negative impact of institutions and norms (which they are part of) on the lives of PLiP. There were only four less positive reflections made on the process: that group dynamics were difficult to manage $(n=2$, papers 19,28); that conflict arose around using PLiP names and images in project materials - with project staff concerned about how being identified as a PLiP or PFLiP could have a negative impact in future (paper 36); that peer researchers' lack of experience or use of personal experience may 'lead' study participants (paper 30); and that involving PLiPs and PFLiPs in a prison context will always involve methodological compromise (paper 20).

\section{Research question four: what were the main obstacles and solutions for overcoming them?}

A number of obstacles to PLiP or PFLiP involvement in research were described. The most frequently reported was that power differences between PLiPs or PFLiPs and academic researchers - amplified when within a hierarchical prison system - meant that the equality inherent in participatory approaches was even more difficult to attain $(n=9$, papers $1,3-5,15,19,20,23,24)$. The impact of prison bureaucracy was also described as a barrier in terms of PLiP availability ( $n=6$, papers: $1,3,5,16,19,20)$, lack of computer/internet access limiting types of involvement and communication $(n=3$, papers $3,16,19)$, room availability and interruptions $(n=3$, papers: $3,5,16)$, and limiting researcher access to PLiPs $(n=2$, papers 20,22). There were also reported barriers to involvement arising from (ex-)PLiP turnover $(n=3$, papers $4,12,33)$, lack of funding and resources $(n=3$, papers: $4,12,22)$, and a lack of staff belief in the process or research $(n=3$, papers: $12,16,19)$. Three papers also specifically detailed the impossibility of involving PLiPs in their research, so much so that they only involved PFLiPs $(n=3$, papers $19,28,35)$. In addition, researchers described dilemmas in conducting research involving PLiPs around voluntariness (papers 5,22), payment (paper 22) and confidentiality (paper 22), as well as university bureaucracy negatively impacting recruitment (paper 28).

In addition, a number of recommendations for the involvement of PLiP and PFLiPs were also made, which included:

- Emphasise staff buy-in (especially senior staff and overall prison governor or warden), common values and goals.

- Ensure adequate funds for the research and staff time to conduct it.

- Designating an administrative worker for the study.

- Training PLiPs for the role and responsibilities expected of them (e.g. facilitating focus groups).

- Not being overly prescriptive about process where PLiP or PFLiPs lead.

- Regularly share feedback of findings and news. 
- Paying researchers for their work (e.g. PLiP involvement could become a work placement to enable this.

- Building evaluation into the research design from the beginning.

\section{Discussion}

\section{Summary of findings}

Most of the included papers used 'participatory' approaches, which are typically bottom-up, community-generated and sometimes explicitly political ways of working, alongside the more apolitical, top-down PPI-type approaches. This was broadly consistent with findings in community studies (Hoekstra et al., 2020), although were more defined in the prison literature (Mockford et al., 2012). PLiP involvement was more collaborative than PLiP-led as opposed to PPI in the community studies (Ocloo \& Matthews, 2016), with PLiPs and PFLiPs involved in most aspects of the research process, although with less involvement in higher-level operations such as funding applications or commissioned projects, and project administration or management. Very few of the studies included an evaluation. Of those that did, these were largely a presentation of PLiP or PFLiP or researcher reflections not subject to any formal analysis, with mostly positive impacts on PLiPs and PFLiPs, the research process, and the team reported. There were very few negative reports - as with community-based studies (Aubin et al., 2019; Ball et al., 2019; Brett et al., 2012; Cook et al., 2019; Mockford et al., 2012). In terms of the barriers, a number of studies discussed similar issues around involvement activities as those carried out in the community but possibly magnified by the prison setting. These included more entrenched power differences, prison bureaucracy, lack of funding and resources, staff attitudes and ethical concerns. It would appear that these issues, which besiege prison research more generally (Charles et al., 2016; James, 2013; Matfin, 2000), present very particular issues for PLiP and PFLiP involvement in the research process that need careful consideration.

\section{Addressing research question five: the feasibility of undertaking a systematic review of the involvement of people in prison?}

With a lack of robust evaluations, there is obviously a high risk of bias in the articles included in this review and, consistent with reviews of public involvement in the community, this makes it difficult to draw any conclusions from the evidence presented. Given the lack of evidence available or found for this review, this would suggest that conducting a full systematic review of the literature may not be feasible until the evidence base is somewhat stronger than it currently is.

\section{Review limitations}

There were a number of aspects of this review that could limit the extent to which the findings can be applied, which derive from: (i) the papers included, and (ii) the way the review was conducted.

\section{(i) The papers included}

The majority of papers included were from high income countries. Whilst this may reflect the languages spoken by the review team members, it is also reflective of the "northern epistemic hegemony" (Aas, 2012) apparent in much research. Given that at least some participatory approaches have their roots in the work of Freire (1970) and more emancipatory, anticolonial and political struggles in low and middle-income countries (Glassman \& Erdem, 2014; Macauley, 2017), it is likely that at least some prison participatory work is happening that is either unpublished or not captured within the review's search strategy due to language barriers.

In addition, a number of the papers were drawn from a research group in Canada, who appeared to run a number of linked research projects funded over a longer period of time which would benefit robust relationship building and involvement activities (Buchanan et al., 2011; Kendall et al., 2020; Martin et al., Martin, Murphy, Chan, et al., 2009, Martin et al., 2013, Martin et al., 2017, Martin et al., 2018; Ramsden et al., 2015). Obviously, this may be different for the more short-term funded studies and timeframes that that many prison projects are conducted within, and therefore not be readily generalisable as they may not be reflective of the type and extent of involvement and relationships possible to develop within that shorter timeframe, which may skew some of the findings of the review. That said, there were some shorter-term studies included, and it is hoped that the findings and recommendations of both the shorter and longer-term projects will be useful.

\section{(ii) The review process}

None of the review team were PLiPs or PFLiPs and, as such, this may limit the analysis. This review was intended as a scoping of the available evidence to assess the feasibility of conducting a full systematic review. Whilst at the present time this would be considered unfeasible, at a later date when the evidence base is more populated, it would be a firm recommendation of this review that the review team would be broadened to include or indeed be led by someone (or team of people) who lives or has lived in prison. 
This review also provided no assessment of study quality. Given that there was a lack of evaluations that could be assessed for quality in a more 'traditional' sense, this was justified. However, there appears to be a need for some form of specific standard assessment of quality of public involvement, both in the community and in prisons, which does not currently exist (Brett et al., 2010). It may be that using a tool such as GRIPP2 (Staniszewska et al., 2017) to record the ways that PLiP or PFLiP involvement is defined and reported, alongside charting the issues raised in the Public Involvement Impact Assessment Framework (Popay, Collins et al., 2014) in a well-described, systematic way, may be useful.

\section{Recommendations}

Further recommendations, aside from those arising from the review limitations, also arose from the combination of difficulties in public involvement generally and its application in a prison setting more specifically. These are:

- Whilst prison staff buy-in is very important in a prison context and may indeed need some local, regional or national government prison policy support, as no research can successfully occur in prisons without addressing these 'gate-keepers' (Matfin, 2000), researcher buy-in is equally important. There is a lack of understanding amongst some researchers of the potentially positive impact of public involvement especially for research quality improvement; hence, education and training at all career stages may be useful (Biggane et al., 2019; Johnson et al., 2018).

- Research in prisons can take a long time to set-up and conduct (Hayes \& Senior, 2007), and involving public in research can take even more time and resources, particularly where PLiPs or PFLiPs need additional training (Domecq et al., 2014). Therefore, it is important that this is adequately accounted for in the commissioning and funding of research, and in making funding applications, as it is possible that PLiP involvement could be marginalized.

- Whilst the issues of payment of PLiPs for their involvement may be controversial, it has been possible to include it as a work or education placement in one of the included papers (Fields et al., 2008). This could indeed be possible in prisons in England and Wales but it would need more centralized government support to facilitate it and, similarly, local, regional or national government support in other jurisdictions;

- Evaluations - some researchers have highlighted the complexity of disentangling the relative contributions of patient and professional researchers (Aubin et al., 2019), whilst others have suggested that this is over-complicating the issue (Boivin et al., 2018). Given the embryonic nature of PLiP involvement in the 'research evidence journey' (Nutley, Powell \& Davies, Nutley et al., 2013), conducting a variety of studies to populate the evidence base ranging from more quantitative and qualitative exploratory studies to more robust evaluations would help to gain a greater understanding of impact, 'what works' and 'what does not work' in this specific context, and develop solutions to barriers regarding power differences, bureaucracy, cultural issues and ethical concerns.

\section{Conclusions}

A number of the findings of this review are consistent with those of reviews undertaken of patient and public involvement in health and social care research in the community - particularly the lack of evaluations, and therefore lack of evidence of effectiveness. There were also similar barriers to implementation, although somewhat amplified by the hierarchical structure of the prison setting. Importantly, this review highlights that there are a number of studies of PLiP or PFLiP involvement across most aspects of the research cycle. However, there is a lack of involvement in higher-level research operations, and indeed PLiP or PFLiP-led research. It is important that this work is more robustly evaluated in order to not only provide evidence of effectiveness, but to more meaningfully explore challenges to PLiP or PFLiP prisoner involvement and to develop practice in the field. The health and social care needs of PLiPs are manifold, and governments are reluctant to grant early release, even to those in very ill health. It is therefore imperative that this particularly vulnerable and disempowered group of people are given voice in health and social care research in order to potentially improve their situation.

\section{Supplementary information}

The online version contains supplementary material available at https://doi. org/10.1186/s40352-021-00154-6.

Additional file 1: Appendix 1. PRISMA-ScR-Fillable-Checklist_09.08.21.

Additional file 2: Appendix 2. Example Search Strategy (initial search).

\section{Acknowledgements}

We would like to especially thank Barney Eden, Anna Haggith, Nuwan Wickramasinghe and Veronica Phillips for their very valuable contributions to this review.

\section{Authors' contributions}

ST was the lead researcher and conceptualised, designed, searched, analysed and interpreted data, and led on writing the manuscript. SM and NS were involved in screening and extracting data as well as reviewing and editing various versions of the manuscript. TVB was the Principle Investigator/Study Lead, contributed towards conceptualisation, design, data quality control, manuscript reviewing and editing, and supervising all aspects of the study. 
ST and TVB carried out the manuscript revisions. All authors read and approved the final manuscript.

\section{Funding}

This is a summary of research funded by the National Institute for Health Research (NIHR) Applied Research Collaboration East of England. Additional sponsorship, as part of the wider prison care programme, was also received from the Cambridgeshire and Peterborough NHS Foundation Trust (CPFT). The views expressed are those of the author(s) and not necessarily those of the NHS, the NIHR or the Department of Health and Social Care.

\section{Availability of data and materials}

All data and materials used in this review are included in this article and its appendices

\section{Declarations}

\section{Ethics approval and consent to participate}

Not applicable.

\section{Consent for publication}

Not applicable.

\section{Competing interests}

The authors declare that they have no competing interests.

\section{Author details}

${ }^{1}$ Hilary Rodham Clinton School of Law, Swansea University, Swansea, UK. ${ }^{2}$ Cambridge Public Health, Department of Psychiatry, School of Clinical Medicine, University of Cambridge, Cambridge, UK. ${ }^{3}$ Leicester School of Allied Health Sciences, De Montfort University, Leicester, UK.

Received: 3 June 2021 Accepted: 31 August 2021

Published online: 11 November 2021

\section{References}

Aas, K. F. (2012). 'The earth is one, but the world is not': Criminological theory and its geopolitical divisions. Theoretical Criminology, 16(1), 5-20. https://doi. org/10.1177/1362480611433433.

Antoniou, T., Mishra, S., Matheson, F., Smith-Merrill, D., Challacombe, L., Rowe, J., ... Strike, C. (2019). Using concept mapping to inform the development of a transitional reintegration intervention program for formerly incarcerated people with HIV. BMC Health Services Research, 19(1), 761. https://doi.org/1 0.1186/s12913-019-4595-y.

Apa, Z. L., Bai, R., Mukherejee, D. V., Herzig, C. T., Koenigsmann, C., Lowy, F. D., \& Larson, E. L. (2012). Challenges and strategies for research in prisons. Public Health Nursing, 29(5), 467-472. https://doi.org/10.1111/j.1525-1446.2012.01027.x.

Arksey, H., \& O'Malley, L. (2005). Scoping studies: Towards a methodological framework. International Journal of Social Research Methodology, 8(1), 19-32. https://doi.org/10.1080/1364557032000119616.

Aubin, D., Hebert, M., \& Eurich, D. (2019). The importance of measuring the impact of patient-oriented research. Canadian Medical Association Journal, 191(31), E860-E864. https://doi.org/10.1503/cmaj.190237.

Awenat, Y. F., Moore, C., Gooding, P. A., Ulph, F., Mirza, A., \& Pratt, D. (2017). Improving the quality of prison research: A qualitative study of ex-offender service user involvement in prison suicide prevention research. Health Expectations, 21(1), 100-109. https://doi.org/10.1111/hex.12590.

Ball, S., Harshfield, A., Carpenter, A., Bertscher, A., \& Marjanovic, S. (2019). Patient and public involvement and engagement in research: Enabling meaningful contribution. RAND Corporation. https://www.rand.org/pubs/research_ reports/RR2678.html. , DOl: https://doi.org/10.7249/RR2678.

Beresford, P. (2002). User involvement in research and evaluation: Liberation or regulation? Social Policy and Society, 1(2), 95-105. https://doi.org/10.1017/S14 74746402000222

Biggane, A. M., Olsen, M., \& Williamson, P. R. (2019). PPI in research: A reflection from early stage researchers. Research Involvement and Engagement, 5(1), 35. https://doi.org/10.1186/s40900-019-0170-2.

Boivin, A., Richards, T., Forsythe, L., Grégoire, A., L'Espérance, A., Abelson, A., \& Carman, K. L. (2018). Evaluating patient and public involvement in research. British Medical Journal, 363, k5147. https://doi.org/10.1136/bmj.k5147.
Brennan, P. K. (2020). Responses taken to mitigate COVID-19 in prisons in England and Wales. Victims \& Offenders, 15(7-8), 1215-1233. https://doi.org/1 0.1080/15564886.2020.1832027.

Brett, J., Staniszewska, S., Mockford, C., Herron-Marx, S., Hughes, J., Tysall, C., \& Suleman, R. (2012). Mapping the impact of patient and public involvement on health and social care research: A systematic review. Health Expectations, 17(5), 637-650. https://doi.org/10.1111/j.1369-7625.2012.00795.x.

Brett, J., Staniszewska, S., Mockford, C., Seers, K., Herron-Marx, S., \& Bayliss, H. (2010). The PIRICOM study: A systematic review of the conceptualisation, measurement, impact and outcomes of patients and public involvement in health and social care research. United Kingdom Clinical Research Collaboration. https://www.ukcrc.org/wp-content/uploads/2014/03/Piricom+ Review+Final+2010.pdf. .

Buchanan, M., Murphy, K., Martin, M. S., Korchinski, M., Buxton, J., Granger-Brown, A., ... Martin, R. E. (2011). Understanding incarcerated women's perspectives on substance use: Catalysts, reasons for use, consequences, and desire for change. Journal of Offender Rehabilitation, 50(2), 81-100. https://doi.org/10.1 080/10509674.2011.546232.

Byng, R., Quinn, C., Sheaff, R., Samele, C., Duggan, S., Harrison, D., Owens, C., Smithson, P., Wright, C., Annison, J., Brown, C., Taylor, R., Henley, W., Qureshi, A., Shenton, D., Porter, I., Warrington, C., \& Campbell, J. (2012). COCOA: Care for Offenders, Continuity of Access. Final Report. National Institute for Health Research. https://www.journalslibrary.nihr.ac.uk/programmes/hsdr/081713210/\#/. .

Care Act UK, 2014. London: The Stationary Office. https://www.legislation.gov.uk/ ukpga/2014/23/contents/enacted.

Charles, A., Rid, A., Davies, H., \& Draper, H. (2016). Prisoners as research participants: Current practice and attitudes in the UK. Journal of Medical Ethics, 42(4), 246-252. https://doi.org/10.1136/medethics-2012-101059.

Clarke, P. (2020). 1 June 2020: Statement from HM chief inspector of prisons, Peter Clarke, on our next steps. HM Inspectorate of Prisons. https://www. justiceinspectorates.gov.uk/hmiprisons/wp-content/uploads/sites/4/2020/06/ PC-statement-010620.pdf. Accessed 04 August 2021.

Cook, N., Siddiqi, N., Twiddy, M., \& Kenyon, R. (2019). Patient and public involvement in low and middle-income countries: A systematic review. BMJ Open, 9(5), e026514. https://doi.org/10.1136/bmjopen-2018-026514.

Cornish, N., Edgar, K., Hewson, A., \& Ware, S. (2016). Social care or systematic neglect? Prison Reform Trust: Older people on release from prison http:// www.prisonreformtrust.org.uk/Portals/0/Documents/Older-prisonerresettlement.pdf.

Crabtree, J. L., Ohm, D., Wall, J. M., \& Ray, J. (2016). Evaluation of a prison occupational therapy informal education program: A pilot study. Occupational Therapy International, 23(4), 401-411. https://doi.org/10.1002/ oti.1442.

Crabtree, J. L., Wall, J. M., \& Ohm, D. (2016). Critical reflections on participatory action research in a prison setting: Toward occupational justice. OTJR: Occupation, Participation and Health, 36(4), 244-252. https://doi.org/10.1177/1 539449216669132

Crewe, B. (2011). Depth, weight, tightness: Revisiting the pains of imprisonment. Punishment \& Society, 13(5), 509-529. https://doi.org/10.1177/1462474 511422172.

Curd, P. R., Winter, S. J., \& Connell, A. (2007). Participative planning to enhance inmate wellness: Preliminary report of a correctional wellness program. Journal of Correctional Health Care, 13(4), 296-308. https://doi.org/10.1177/1 078345807306754

Department of Health (1999). The future organisation of prison health care. Department of Health. https://webarchive.nationalarchives.gov.uk/20110504 020423/http://www.dh.gov.uk/prod_consum_dh/groups/dh_digitalassets/ @dh/@en/documents/digitalasset/dh_4106031.pdf. Accessed 04 August 2021.

Domecq, J. P., Prutsky, G., Elraiyah, T., Wang, Z., Nabhan, M., Shippee, N., ... m Dabrh, A. M. A., \& Murad, M. H. (2014). Patient engagement in research: A systematic review. BMC Health Services Research, 14(1), 89. https://doi.org/1 0.1186/1472-6963-14-89.

Edge, C., Stockley, R., Swabey, L., King, E., Decodts, F., Hard, J., \& Black, G. (2020). Secondary care clinicians and staff have a key role in delivering equivalence of care for prisoners: A qualitative study of prisoners' experiences. EClinicalMedicine, 24, 100416. https://doi.org/10.1016/j.eclinm.2020.100416.

Fields, J., González, I., Hentz, K., Rhee, M., \& White, C. (2008). Learning from and with incarcerated women: Emerging lessons from a participatory action study of sexuality education. Sexuality Research \& Social Policy, 5(2), 71-84. https://doi.org/10.1525/srsp.2008.5.2.71. 
Forsyth, K., Archer-Power, L., Senior, J., Meacock, R., Webb, R., Emsley, R., ... Shaw, J. (2017). The effectiveness of the older prisoner health and social Care assessment and plan (OHSCAP): A randomised controlled trial. Health Services and Delivery Research, 5(31), 31-186. https://doi.org/10.3310/hsdr05310.

Forsyth, K., Heathcote, L., Senior, J., Malik, B., Meacock, R., Perryman, K., ... Shaw, J. (2020). Dementia and mild cognitive impairment in prisoners aged over 50 years in England and Wales: A mixed-methods study. Health Services and Delivery Research, 8(27), 27-116. https://doi.org/10.3310/hsdr08270.

Freire, P. (1970). Pedagogy of the oppressed. London: Penguin.

Glassman, M., \& Erdem, G. (2014). Participatory action research and its meanings: Vivencia, praxis, conscientization. Adult Education Quarterly, 64(3), 206-221. https://doi.org/10.1177/074171361452366.

Hassan, L., Frisher, M., Senior, J., Tully, M., Webb, R., While, D., \& Shaw, J. (2014). A cross-sectional prevalence survey of psychotropic medication prescribing patterns in prisons in England. Health Services and Delivery Research, 2(33), 182. https://doi.org/10.3310/hsdr02330.

Hatton, D. C., \& Fisher, A. A. (2011). Using participatory methods to examine policy and women prisoners' health. Policy, Politics, \& Nursing Practice, 12(2), 119-125. https://doi.org/10.1177/1527154411412384.

Hatton, D. C., Kleffel, D., \& Fisher, A. A. (2006). prisoners' perspectives of health problems and healthcare in a US women's jail. Women \& Health, 44(1), 119136. https://doi.org/10.1300/J013v44n01_07.

Hayes, A., \& Senior, J. [Eds] (2007). Researchers' handbook: A guide for researchers in prison health. $3^{\text {rd }}$ Edition. Prison Health Research Network. http://www. ohrn.nhs.uk/toolkit/Handbook3rdEd.pdf. Accessed 04 August 2021.

Hayes, A. J., Burns, A., Turnbull, P., \& Shaw, J. J. (2012). The health and social care needs of older male prisoners. International Journal of Geriatric Psychiatry, 27(11), 1155-1162. https://doi.org/10.1002/gps.3761.

Health and Social Care Committee (2018). Prison health: Twelfth report of session 2017-19. House of Commons. https://publications.parliament.uk/pa/cm20171 9/cmselect/cmhealth/963/963.pdf. Accessed 04 August 2021

Health Research Authority (2017). UK policy framework for health and social care research. Health Research Authority. https://www.hra.nhs.uk/planning-andimproving-research/policies-standards-legislation/uk-policy-framework-healthsocial-care-research/. Accessed 04 August 2021.

Her Majesty's Prison \& Probation Service (2020). COVID-19 operational guidance exceptional regime \& senvice delivery. Version 3.0. Her Majesty's Prison \& Probation Service. https:/howardleague.org/wp-content/uploads/2020/05/1.-Exceptionalregime-and-service-delivery-27.03.20_Redacted.pdf. Accessed 04 August 2021.

Hoekstra, F., Mrklas, K. J., Khan, M., McKay, R. C., Vis-Dunbar, M., Sibley, K. M., ... Gainforth, H. L. (2020). A review of reviews on principles, strategies, outcomes and impacts of research partnerships approaches: A first step in synthesising the research partnership literature. Health Research Policy and Systems, 18(51), 51. https://doi.org/10.1186/s12961-020-0544-9.

Howerton, A., Burnett, R., Byng, R., \& Campbell, J. (2009). The consolations of going back to prison: What 'revolving door' prisoners think of their prospects. Journal of Offender Rehabilitation, 48(5), 439-461. https://doi.org/1 0.1080/10509670902979710

INVOLVE (2012). Briefing note two: What is public involvement in research? INVOLVE. https://www.invo.org.uk/posttyperesource/what-is-publicinvolvement-in-research/.

Jacobs, L., Komashie, A., Lombardo, C., \& Clarke, G. (2017). Patient and public involvement (PPI) in research handbook. Collaboration for Leadership in Applied Health Research and Care East of England. https://www.clahrc-eoe. nihr.ac.uk/wp-content/uploads/2018/01/CLAHRC-EoE-PPI-IN-Research-Ha ndbook_December-2017.pdf. Accessed 04 August 2021.

James, N. (2013). Research on the 'inside': The challenges of conducting research with young offenders. Sociological Research Online, 18(4), 138-147. https://doi. org/10.5153/sro.3129.

Johnson, M. E., Brems, C., Mills, M. E., \& Eldridge, G. D. (2018). Involving incarcerated individuals in the research process: Perspective of key stakeholders. Action Research, 16(1), 43-64. https://doi.org/10.1177/147675031 6661397.

Kendall, S., Lighton, S., Sherwood, J., Baldry, E., \& Sullivan, E. A. (2020). Incarcerated Aboriginal women's experiences of accessing healthcare and the limitations of the 'equal treatment' principle. International Journal for Equity in Health, 19(1), 48. https://doi.org/10.1186/s12939-020-1155-3.

Lander, J., Langhof, H., \& Dierks, M. (2019). Involving patients and the public in medical and health care research studies: An exploratory survey on participant recruiting and representativeness from the perspective of study authors. PLoS One, 14(1), e0204187. https://doi.org/10.1371/journal.pone.0204187.
Lee C, Haggith A, Mann N, Kuhn I, Cater F, Eden B, Van Bortel T (2016) Older prisoners and the Care Act 2014: An examination of policy, practice and models of social care delivery. Prison Service Journal, 224, 35-41. ISSN 20464215.

Lee C, Treacy S, Haggith A, Wickramasinghe ND, Cater F, Kuhn I, Van Bortel T. (2019). A systematic integrative review of programmes addressing the social care needs of older prisoners. Health Justice, 7(1), 9. https://doi.org/10.1186/s4 0352-019-0090-0. PMID: 31134392; PMCID: PMC6717991.

Macauley, A. C. (2017). Participatory research: What is the history? Has the purpose changed? Family Practice, 34(3), 256-258. https://doi.org/10.1093/fa $\mathrm{mpra} / \mathrm{cmw} 117$

Madden, M., \& Speed, E. (2017). Beware zombies and unicorns: Toward critical patient and public involvement in health research in a neoliberal context. Frontiers in Sociology, 2. https://doi.org/10.3389/fsoc.2017.00007.

Marjanovic, S., Harshfield, A., Carpenter, A., Bertscher, A., Punch, D., \& Ball, S. (2019). Involving patients and the public in research. THIS Institute. https:// www.thisinstitute.cam.ac.uk/research-articles/involving-patients-public-resea rch/. Accessed 04 August 2021.

Martin, R. E., Adamson, S., Korchinski, M., Granger-Brown, A., Ramsden, V. R., Buxton, J. A., ... Hislop, T. G. (2013). Incarcerated women develop a nutrition and fitness program: Participatory research. International Journal of Prisoner Health, 9(3), 142-150. https://doi.org/10.1108/IJPH-03-2013-0015.

Martin, R. E., Korchinski, M., Fels, L., \& Leggo, C. (2017). Arresting hope: Women taking action in prison health inside out. Cogent Arts \& Humanities, 4(1). https://doi.org/10.1080/23311983.2017.1352156.

Martin, R. E., Murphy, K., Chan, R., Ramsden, V. R., Granger-Brown, A., Macaulay, A. C., ... Hislop, T. G. (2009). Primary health care: Applying the principles within a community-based participatory health research project that began in a Canadian women's prison. Global Health Promotion, 16(4), 43-53. https://doi. org/10.1177/1757975909348114

Martin, R. E., Murphy, K., Hanson, D., Hemingway, C., Ramsden, V., Buxton, J., ... Hislop, T. G. (2009). The development of participatory health research among incarcerated women in a Canadian prison. International Journal of Prisoner Health, 5(2), 95-107. https://doi.org/10.1080/17449200902884021.

Martin, R. E., Turner, R., Howett, L., Howard, T., Hanberg, D., Buxton, J. A., ... Oliffe, J. L. (2018). Twelve committed men: The feasibility of a community-based participatory HIV-prevention intervention within a Canadian men's correctional facility. Global Health Promotion, 25(3), 6-14. https://doi.org/10.11 77/1757975916659045.

Matfin, C. (2000). Doing research in a prison setting. In V. Jupp, P. Davoes, \& P. Francis (Eds.), Doing criminological research, (pp. 215-233). London: Sage.

McLeod, K. E., Korchinski, M., Young, P., Milkovich, T., Hemingway, C., DeGroot, M., .. Martin, R. E. (2020). Supporting women leaving prison through peer health mentoring: A participatory health research study. CMAJ Open, 8(1), E1E8. https://doi.org/10.9778/cmajo.20190106.

Meyer, K., \& Fels, L. (2009). Breaking out: Learning research from 'the women in prison' project. International Review of Qualitative Research, 2(2), 269-290. https://doi.org/10.1525/irqr.2009.2.2.269.

Mockford, C., Staniszewska, S., Griffiths, F., \& Herron-Marx, S. (2012). The impact of patient and public involvement on UK NHS health care: A systematic review. International Journal for Quality in Health Care, 24(1), 28-38. https://doi.org/1 0.1093/intqhc/mzr066.

Morgan, K. (2016). Patient and public involvement in research, why not? McPin Foundation. https://mcpin.org/wp-content/uploads/talking-point-paper-2.pdf.

Munn, Z., Peters, M. D. J., Stern, C., Tufanaru, C., McArthur, A., \& Aromataris, E. (2018). Systematic review or scoping review? Guidance for authors when choosing between a systematic or scoping review approach. BMC Medical Research Methodology, 18(1), 143. https://doi.org/10.1186/s12874-018-0611-x.

Nutley, S., Powell, A., \& Davies, H. (2013). What counts as good evidence? Provocation paper for the Alliance for useful. Evidence: St Andrews University https://www.alliance4usefulevidence.org/assets/What-Counts-as-GoodEvidence-WEB.pdf.

Ocloo, J., \& Matthews, R. (2016). From tokenism to empowerment: Progressing patient and public involvement in healthcare improvement. BMJ Quality and Safety, 25(8), 626-632. https://doi.org/10.1136/bmjqs-2015-004839.

Perrett, S. E., Gray, B. J., L. G., D. E., \& Brooks, N. J. (2020). Exploring health and wellbeing in prison: A peer research approach. International Journal of Prisoner Health, 16(1), 78-92. doi:https://doi.org/10.1108/IJPH-03-2019-0019.

Popay, J., Collins, M., \& with the PiiAF Study Group (2014). PiiAF: The public involvement impact assessment framework. Liverpool \& Exeter: Universities of Lancaster http://piiaf.org.uk/documents/piiaf-guidance-jan14.pdf. . 
Popay, J., Roberts, H., Sowden, A., Petticrew, M., Arai, L., Rodgers, M., ... Duffy, S. (2006). Guidance on the conduct of narrative synthesis in systematic reviews: A product from the ESRC methods programme. Lancaster University https:// www.lancaster.ac.uk/media/lancaster-university/content-assets/documents/ fhm/dhr/chir/NSsynthesisguidanceVersion1-April2006.pdf. .

Prison Reform Trust (2020). How prisons are responding to Covid-19: Briefing 1 Families and communications. Prison Reform Trust. http://www. prisonreformtrust.org.uk/Portals/0/Documents/CAPPTIVE_families_webfinal. pdf. Accessed 04 August 2021.

Ramsden, V., Martin, R., McMillan, J., Granger-Brown, A., \& Tole, B. (2015). Participatory health research within a prison setting: A qualitative analysis of 'Paragraphs of Passion'. Global Health Promotion, 22(4), 48-55. https://doi. org/10.1177/1757975914547922.

Revolving Doors Agency (2016). Improving your prisoner involvement systems: A toolkit for staff. Revolving Doors Agency. http://www.revolving-doors.org.uk/ file/1863/download?token=1cQMWr1W. Accessed 04 August 2021.

Richardson, W. S., Wilson, M. C., Nishikawa, J., \& Hayward, R. S. A. (1995). The wellbuilt clinical question: A key to evidence-based decisions. ACP journal Club, 123, A12-A13. Doi:0.7326/ACPJC-1995-123-3-A12.

Russell, J., Greenhalgh, T., \& Taylor, M. (2019). Patient and public involvement in NIHR research 2006-2019: Policy intentions, progress and themes. National Institute for Health Research. https://oxfordbrc.nihr.ac.uk/wpcontent/uploads/2019/05/NIHR-and-PPI-report-Feb_2019.pdf. Accessed 04 August 2021.

Rutter, D., Francis, J., Coren, E., \& Fisher, M. (2010). SCIE systematic research reviews: Guidelines. Social Care Institute of Excellence. https://www.scie.org. uk/publications/researchresources/rr01.asp. Accessed 04 August 2021.

Samele, C., Thomas, S., Keil, J., Sherlock, J., \& Durcan, G. (2008). A review of service user involvement in prison mental health research. Sainsbury Centre for Mental Health.

Sherwood, J., \& Kendall, S. (2013). Reframing spaces by building relationships: Community collaborative participatory action research with Aboriginal mothers in prison. Contemporary Nurse, 46(1), 83-94. https://doi.org/10.5172/ conu.2013.46.1.83.

Senior J, Forsyth K, Walsh E, O'Hara K, Stevenson C, Hayes A, et al. (2013). Health and social care services for older male adults in prison: the identification ofcurrent service provision and piloting of an assessment and care planning model. Health Services and Delivery Research, 1(5). https://doi.org/10.3310/ hsdr01050.

South, J., Bagnall, A., Hulme, C., Woodall, J., Longo, R., Dixey, R., ... Wright, J. (2014). A systematic review of the effectiveness and cost-effectiveness of peer-based interventions to maintain and improve offender health in prison settings. Health Services Delivery Research, 2(35), 1-218. https://doi.org/10.331 0/hsdr02350.

Staley, K. (2009). Exploring impact: Public involvement in NHS, public health and social care research. National Institute for Health Research. http://www.invo. org.uk/wp-content/uploads/2011/11/Involve_Exploring_Impactfinal28.10.09. pdf. Accessed 04 August 2021

Staniszewska, S., Brett, J., Simera, I., Seers, K., Mockford, C., Goodlad, S., ... Tysall, C. (2017). GRIPP2 reporting checklists: Tools to improve reporting of patient and public involvement in research. British Medical Journal, 358, j3453. https://doi. org/10.1136/bmj.j3453.

Sturge, G. (2020). UK prison population statistics. House of Commons Library. https://commonslibrary.parliament.uk/research-briefings/sn04334/. Accessed 04 August 2021.

Sullivan, E., Hassal, P., \& Rowlands, D. (2008). Breaking the chain: A prison-based participatory action research project. British Journal of Forensic Practice, 10(3), 13-19. https://doi.org/10.1108/14636646200800015.

Taylor, C., Gill, L., Gibson, A., Byng, R., \& Quinn, C. (2018). Engaging "seldom heard" groups in research and intervention development: Offender mental health. Health Expectations, 21(6), 1104-1110. https://doi.org/10.1111/hex.12 807.

Townsend, D. (2001). Prisoners with HIV/AIDS: A participatory learning and action initiative in Malaysia. Tropical Doctor, 31(1), 8-10. https://doi.org/10.1177/004 947550103100103.

Treacy, S., Haggith, A., Wickramasinghe, N. D., \& Van Bortel, T. (2019). Dementiafriendly prisons: A mixed-methods evaluation of the application of dementiafriendly community principles to two prisons in England. BMJ Open, 9(8), e030087. https://doi.org/10.1136/bmjopen-2019-030087.

Tricco, A. C., Lillie, E., Zarin, W., O’Brien, K. K., Colquhoun, H., Levac, D., et al. (2018). PRISMA extension for scoping reviews (PRISMA-SCR): Checklist and explanation. Annals of Internal Medicine, 169(7), 467-473. https://doi.org/10. 7326/M18-0850.

User Voice. (2016). Spice: The bird killer - what prisoners think about the use of spice and other legal highs in prison. User Voice. https://www.uservoice.org/ wp-content/uploads/2020/07/User-Voice-Spice-The-Bird-Killer-Reportcompressed.pdf. Accessed 04 August 2021.

Ward, J., \& Bailey, D. (2011). At arms length: The development of a self-injury training package for prison staff through service user involvement. The Journal of Mental Health Training, Education, and Practice, 6(4), 175-185. https://doi.org/10.1108/17556221111194518.

Ward, J., \& Bailey, D. (2012). Consent, confidentiality and the ethics of PAR in the context of prison research. Studies in Qualitative Methodology, 12, 149-169. https://doi.org/10.1108/S1042-3192(2012)0000012011.

Ward, J., \& Bailey, D. (2013). A participatory action research methodology in the management of self-harm in prison. Journal of Mental Health, 22(4), 306-316. https://doi.org/10.3109/09638237.2012.734645.

Ward, J., Bailey, D., \& Boyd, S. (2012). Participatory action research in the development and delivery of self-harm awareness sessions in prison: Involving service users in staff development. Prison Service Journal, 202, 20-25.

Williams, B. A., Stern, M. F., Mellow, J., Safer, M., \& Greifinger, R. B. (2012). Aging in correctional custody: Setting a policy agenda for older prisoner health care. American Journal of Public Health, 102(8), 1475-1481. https://doi.org/10.21 05/AJPH.2012.300704.

\section{Publisher's Note}

Springer Nature remains neutral with regard to jurisdictional claims in published maps and institutional affiliations.

\section{Ready to submit your research? Choose BMC and benefit from:}

- fast, convenient online submission

- thorough peer review by experienced researchers in your field

- rapid publication on acceptance

- support for research data, including large and complex data types

- gold Open Access which fosters wider collaboration and increased citations

- maximum visibility for your research: over $100 \mathrm{M}$ website views per year

At $\mathrm{BMC}$, research is always in progress.

Learn more biomedcentral.com/submissions 